\title{
Aula de campo no projeto TAMAR: conscientizando alunos do nível 1 da educação infantil, sobre os cuidados e sobrevivência das tartarugas no habitat de proteção
}

\author{
Lucilene Emidio Domingos $^{1}$; José Geraldo Ferreira da Silva ${ }^{2}$
}

\begin{abstract}
Resumo: Alunos da Educação Infantil realizam atividades diversificadas dentro e fora de sala de aula juntos de seus professores, em espaços formal e não formal, levando consigo conhecimentos prévios para a aula de campo, onde expressaram suas curiosidades relacionadas ao meio ambiente que foram visitar. O objetivo deste artigo é conhecer a vida da tartaruga marinha; reconhecer algumas interações entre seres vivos e conscientizar sobre questões ambientais pensando na preservação da espécie animal e cuidados com o meio ambiente marinho através do projeto TAMAR. Para coleta de dados foram realizadas observações e desenvolvimentos de planejamentos com alunos do nível 1 por 10 dias letivos. Os dados que foram colhidos e analisados de forma descritivas e interpretativa. Conforme as aula iam acontecendo os alunos mostraram bastante interesse em conhecer e aprimorar os conhecimentos, o entusiasmo dos aluno foi ainda maior na aula de campo no Projeto TAMAR a sensibilização diante que eles viam foi verificado de acordo com as reações de gritos eufóricos, gargalhadas, perguntas a monitora do projeto TAMAR, admiração frente as informações recebidas e espanto visto que muitas tartarugas morrem por causa do lixo que são jogados no mar.
\end{abstract}

Palavras chave: Meio Ambiente. Educação Ambiental. Projeto TAMAR. Aula de Campo e Sensibilização.

\section{Field lesson in the TAMAR project: raising awareness among students of level 1 of early childhood education about the care and survival of turtles in the protection habitat}

\begin{abstract}
Early Childhood Education students carry out diverse activities inside and outside the classroom together with their teachers, in formal and non-formal spaces, taking with them previous knowledge for the field class, where they expressed their curiosities related to the environment they went to visit. The purpose of this article is to learn about the life of the sea turtle; recognize some interactions between living beings and raise awareness about environmental issues with a view to preserving the animal species and taking care of the marine environment through the TAMAR project. For data collection, observations and planning developments were carried out with level 1 students for 10 school days. The data that were collected and analyzed in a descriptive and interpretative way. As the classes were going on, the students showed a lot of interest in knowing and improving their knowledge, the students' enthusiasm was even greater in the field class at the TAMAR Project. questions the monitor of the TAMAR project, admiration at the information received and astonishment as many turtles die because of the garbage that is thrown into the sea.
\end{abstract}

Keywords: Environment. Environmental education. Tamar project. Field and Awareness Class.

\footnotetext{
${ }^{1}$ Mestranda do programa de mestrado em Ciências Tecnologia e Educação na Faculdade Vale do Cricaré (FVC) em São Matheus Espírito Santo. lucilene2976@gmail.com;

${ }^{2}$ Professor Doutor do Programa de Mestrado em Ciências, Tecnologia e Educação Dr. José Geraldo Ferreira da Silva
} 


\section{Introdução}

A discussão a respeito do nosso meio ambiente, nos leva a pensarmos nos nossos alunos, tendo em mente a necessidade de levar os mesmos a intuir sobre o assunto, independentemente da idade que tenham os pequenos. Devemos lembrar que a sociedade está sempre cobrando e exigindo, um cidadão crítico e reflexivo, quanto ao meio ambiente e a preservação do mesmo. Daí cabe a nós Educadores, essa conscientização.

Acreditam alguns autores que, quanto mais cedo os estudantes receberem informações e compreenderem os problemas ambientais, mais cedo tornar-se-ão fortes aliados na sua preservação e conservação.

A poluição das águas pelo lixo, esgoto e/ou petróleo também tendem a trazer grandes prejuízos ao ciclo da vida da vida marinha, especialmente as tartarugas, pois interferem na sua dieta e locomoção (MACEDO et al, 2011; MURMAN et al, 2005).

Desta forma, pesamos e levamos os alunos a terem este contado direto com os animais marinhos através do projeto TAMAR. Tal iniciativa potencializa a sensibilização e o convívio com esse ambiente, de maneira natural. Em alguns casos observando a adaptação quando dos cuidados de animais em recuperação, tendo como ganho um aprendizado muito especial sobre a valorização dos aspectos afetivos.

Pode-se verificar na nossa constituição de 1988, uma lei federal que visa a conscientização de todos para o cuidado com o meio ambiente. Foi um marco na Educação Ambiental no Brasil, presente no art. 225, VI e, posteriormente, na Lei n. 9795, de 27/04/1999.

\footnotetext{
Art. 225- Todos têm direito ao meio ambiente ecologicamente equilibrado, bem de uso comum do povo e essencial à sadia qualidade de vida, impondo-se ao Poder Público e à coletividade o dever de defendê-lo e preservá-lo para as presentes e futuras gerações. VI- promover a educação ambiental em todos os níveis de ensino e a conscientização pública para a preservação do meio ambiente. (BRASIL. CONSTITUIÇÃO FEDERAL, 1998).
}

As aulas de campo possibilitam aos alunos e professores, uma aquisição ainda maior nos conhecimentos, potencializadas pela observação. $\mathrm{O}$ ponto culminante são as rodas de conversas que ocorrem na sala de aula, após as vivências em campo. Fatos relevantes para a aprimoramento dos conhecimentos são discutidos e, aproveita-se para fazer a interação dos conteúdos com os de outras da Educação Infantil.

Segundo o sociólogo Corsaro (2011), as crianças são agentes sociais, ativos e criativos que, na interação com os grupos sociais com que se relacionam e, com os contextos de vida em 
que estão inseridos. Produzem suas próprias e exclusivas culturas infantis, ao tempo em que contribuem para a produção da sociedade.

Em Vitória Espírito Santo existem inúmeros espaços de preservação ao meio ambiente, que possibilitam às escolas uma rica integração com os conteúdos de sala de aula. Planejamentos e visitas devem ser estimulados, tornando os estudantes mais próximos e em contato direto com a natureza e a biodiversidade.

O projeto TAMAR tem por objetivo proteger as tartarugas marinhas. Com o passar dos anos, surgiu a necessidade de conscientizar as populações costeiras, de forma que os seus habitantes pudessem ser parceiros na preservação e cuidado com o mar, como um habitat importante para a biodiversidade ali existente.

As ações de conservação e pesquisas, educação ambiental e outras ações de conscientização da importância da conservação de tais ambientes é que vem mantendo este projeto. Desde então, a expressão TAMAR passou a designar o Programa Nacional de Conservação de Tartarugas Marinhas, executado em cooperação entre o Centro Brasileiro de Proteção e Pesquisa das Tartarugas Marinhas-Centro TAMAR. Este último, vinculado à Diretoria de Biodiversidade do Instituto Chico Mendes da Biodiversidade-ICMBio, órgão do Ministério do Meio Ambiente. A Fundação Pró-TAMAR, é uma instituição não governamental, sem fins lucrativos, fundada em 1988 e considerada de Utilidade Pública Federal desde 1996.

Ao levamos os alunos da Educação Infantil para visitar este espaço, colocamos em prática as observações e explicações já vivenciadas em sala de aula, no laboratório de Informática e, nas as atividades afins já realizadas. Procura-se fazer uma integração dos conteúdos com tudo que foi observado. É grande a curiosidade dos alunos. Nos momentos de visitas aos espaços de observações, observam-se vídeos. Mas é a observação direta, o toque e a aproximação real o fator que mais motiva.

De acordo com Lima e Assis (2005, p. 112), o trabalho de campo se configura como um recurso importante para o aluno compreender o lugar e o mundo, articulando a teoria à prática, através da observação e da análise do espaço vivido e concebido.

Observa-se maior engajamento e que mais facilmente os objetivos eram alcançados, por meio daquilo que foi proposto para aquisição dos conhecimentos, a medida que acontecem a visitação e as discussões.

Conforme Lima (1989, p. 30), [...] o espaço físico isolado do ambiente só existe na cabeça dos adultos para medi-lo, para vendê-lo, para guardá-lo. Para a criança existe o espaço alegria, o espaço medo, o espaço proteção, o espaço mistério, o espaço descoberta, enfim, os espaços de liberdade ou de opressão. 
Os espaços trazem um caráter educativo para os alunos, quando visitam o projeto TAMAR. As instalações permitem um deslocamento e acessibilidade para todos, auxiliando os professores, já que contam com monitores treinados e preparados para acompanhar os alunos por meio das explicações.

O objetivo das visitas, normalmente é conhecer a vida da tartaruga marinha; vivenciar algumas interações com outros seres vivos e, conscientizar sobre questões ambientais pensando na preservação da espécie animal e cuidados com o meio ambiente marinho.

\section{Procedimentos Metodológicos}

O projeto constou de duas fases: A primeira fase em sala de aula; a segunda foi em aula de campo em um centro de pesquisa e proteção de tartarugas marinhas -projeto TAMAR. Ambiente especial para visitação e expansão do conhecimento marinho.

Trata-se de um estudo qualitativo e descritivo. Realizou-se várias observações sequenciais no período de 10 dias letivos na segunda quinzena do mês de outubro. A aula de campo aconteceu no dia 27/10/2017. Os relatos foram coletados ao longo das aulas na escola, com a turma da Educação Infantil e, durante a aula de campo.

Neste período foram registrados elementos significativos que mostraram a sensibilização nas falas das crianças.

Conforme as aulas aconteciam pode-se ver nas indagações, que os alunos da Educação infantil mostravam-se mais de curiosos e motivados. Segundo Martins (2010) são maneiras de alertar os indivíduos para questões ambientais. Foram registradas as falas das crianças envolvidas, sempre levando para eles informações novas e imagens relacionadas com as tartarugas marinhas. Foi dada uma oportunidade de trazer para a sala uma pequena tartaruga, em determinado momento de aula expositiva. A tartaruguinha da água doce, de ouvido vermelho (Figura 1). Foi um momento intenso e de grande euforia. Risos, admiração, medo, gritos de alegria, foram formas de expressarem seu interesse em conhecer o pequeno animal (Figura 2). 


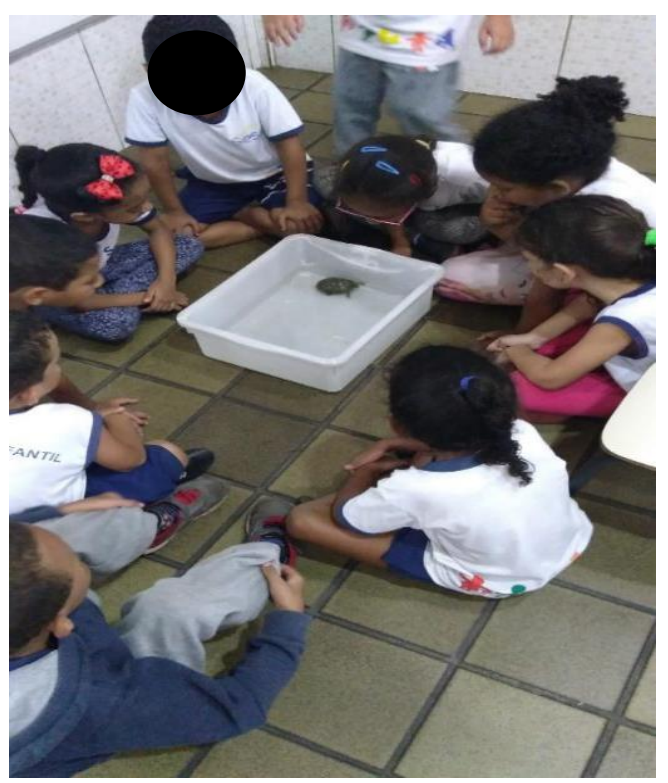

Figura1 - Detalhe da pequena tartaruga apresentada em sala de aula

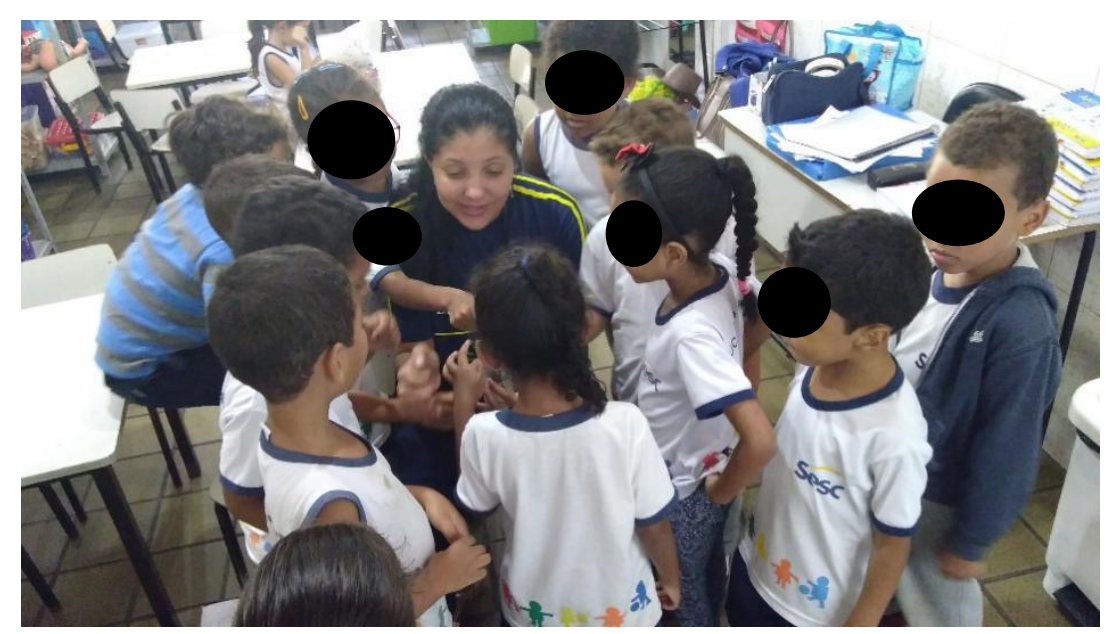

Figura 2 - Interesse dos alunos ao serem apresentados a tartaruguinha.

Com a observação direta notou-se a curiosidade dos alunos e, a expectativa para o dia da aula de campo, o que permitiu a concretização do tema já apresentado por meio das aulas expositivas. Vídeos foram assistidos e atividades realizadas anteriormente a este momento. A visita da tartaruguinha proporcionou uma reflexão sobrea importância dos cuidados, já antes mencionados de uma forma dialógica.

A tartaruga assume um papel proeminente e inspirador. (...) Graças aos múltiplos esforços empregando a tartaruga como espécie bandeira, áreas de proteção marinhas e costeiras têm sido criadas (...) e beneficiam outras espécies através da proteção de seus respectivos habitats. (MARCOVALDI et al., 2005) 
As atividades realizadas, nos mostram que os objetivos foram alcançados. A ilustração tem riqueza de detalhes, onde a aluna desenhou a professora passando informações para os alunos em uma roda de conversa, detalhando ricamente este momento de aprendizagem (Figura $3)$.

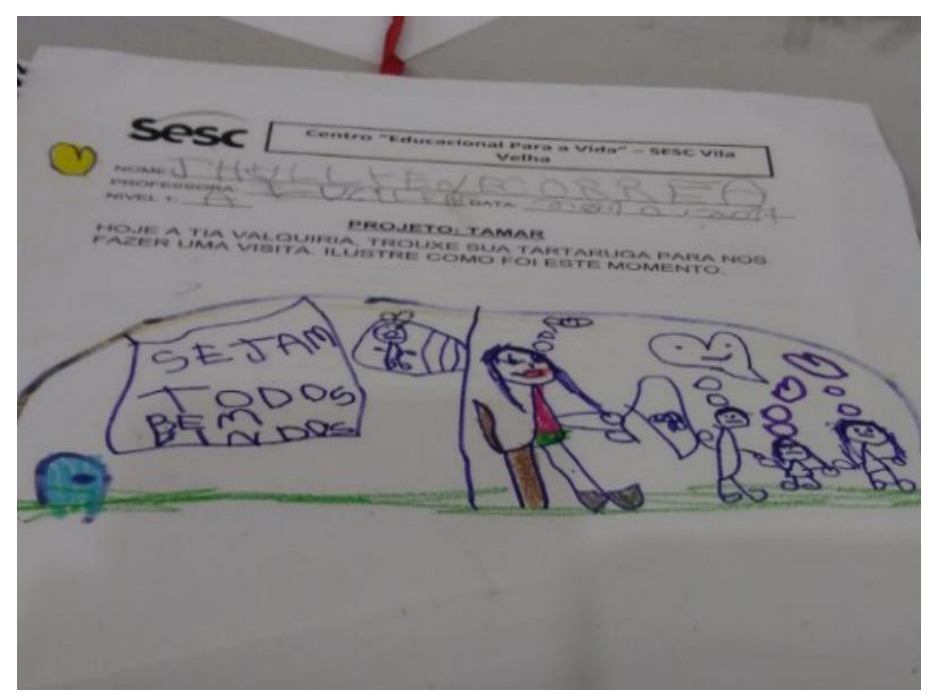

Figura 3 - Atividades de registro do aprendizado em roda de conversar com observação da tartaruga.

\section{Resultados}

\section{Analisando as falas dos alunos da Educação Infantil nível 1}

Ao observar as falas dos alunos da Educação Infantil, vimos que a maioria delas não é propriamente uma pergunta pensada. São expressões das interações manifestadas através de reações como gritos, risos, expressões de espanto e, muita admiração ao que é observado. As indagações e reações dos alunos foram anotadas, observando-se as relações com as perguntas elaboradas pela professora.

As falas das crianças foram organizadas em 5 passos: 1) reações; 2) curiosidade; 3) perguntas e observações diante o ambiente ao redor 4) interesses em conhecer outros espaços do projeto TAMAR; 5) Conhecimentos prévios.

Na sequência descreve-se cada categoria: 
Reações - Pode-se observar nesta categoria as reações dos alunos, de maneira bem espontânea. Os risos, gritos e gargalhadas fizeram parte de todo o contexto no qual os alunos estavam inseridos neste momento onde misturavam as observações frente ao compromisso de explorar todo o espaço pesquisado: olha que lugar lindo! A televisão é grandona! Gente tem parquinho! Olha as tartarugas! Aquelas tartarugas são de mentirinha! Professora aqui tem piscinas! Gente olha o tamanho daquela tartaruga! Eu vi um caranguejo! Olha o ouriço! Corre gente tem mais tartaruga aqui! Uau que grandona! Professora esta é maior que a senhora! Professora elas sai da piscina?

Curiosidade- Pode-se observar que as curiosidades e as expressões aconteciam de acordo com o que era contemplado pelos alunos da Educação Infantil, presentes na fauna do espaço de visitação, levando-se em conta os conhecimentos prévios. Fuentes (2012) diz que a curiosidade natural da criança a direciona a um verdadeiro interesse científico estimulando-a a explorar seu encontro.

"Gente, olha ali, olha ali!"; "Lá na piscina grande"; "olha aqui tem passarinho branco e preto!"; "As tartarugas são de vários tamanhos, por quê professora?"; "Cara a tartaruga não para de nadar!”

Perguntas e observações diante o ambiente ao redor: conforme os alunos iam falando pudemos observar a sua perspicácia. Sempre nos percursos que percorridos, os alunos demostravam muito interesse frente a tudo e, passavam a formular novas perguntas com o que a monitora ia explicando.

Um aluno avistou um mirante e perguntou: “o que tem lá em cima?”. Neste percurso eles quase não perguntaram, mas gostaram de observar um fóssil de uma tartaruga gigante, havia também um informativo em um quadro com uma imagem de uma tartaruga e várias informações. Ferreira e Mello (2012, p.18) enfatizam que "Deve-se dar maior visibilidade para as perguntas das crianças[...] e mostrar como os "pequenos pensadores" estão pensado".

A curiosidade frente ao quadro de informações sobre a tartaruga gigante foi surpreendente todos os alunos ficaram fascinados e prestaram bastante atenção nas informações recebidas da monitora que nos acompanhava. (Figura - 4) da mesma forma ao se depararem com os fosses dos animais marinhos os olhares e atenção ficaram ainda mais atentos diante de todas as informações que lhe eram passada ( Figura - 5) 


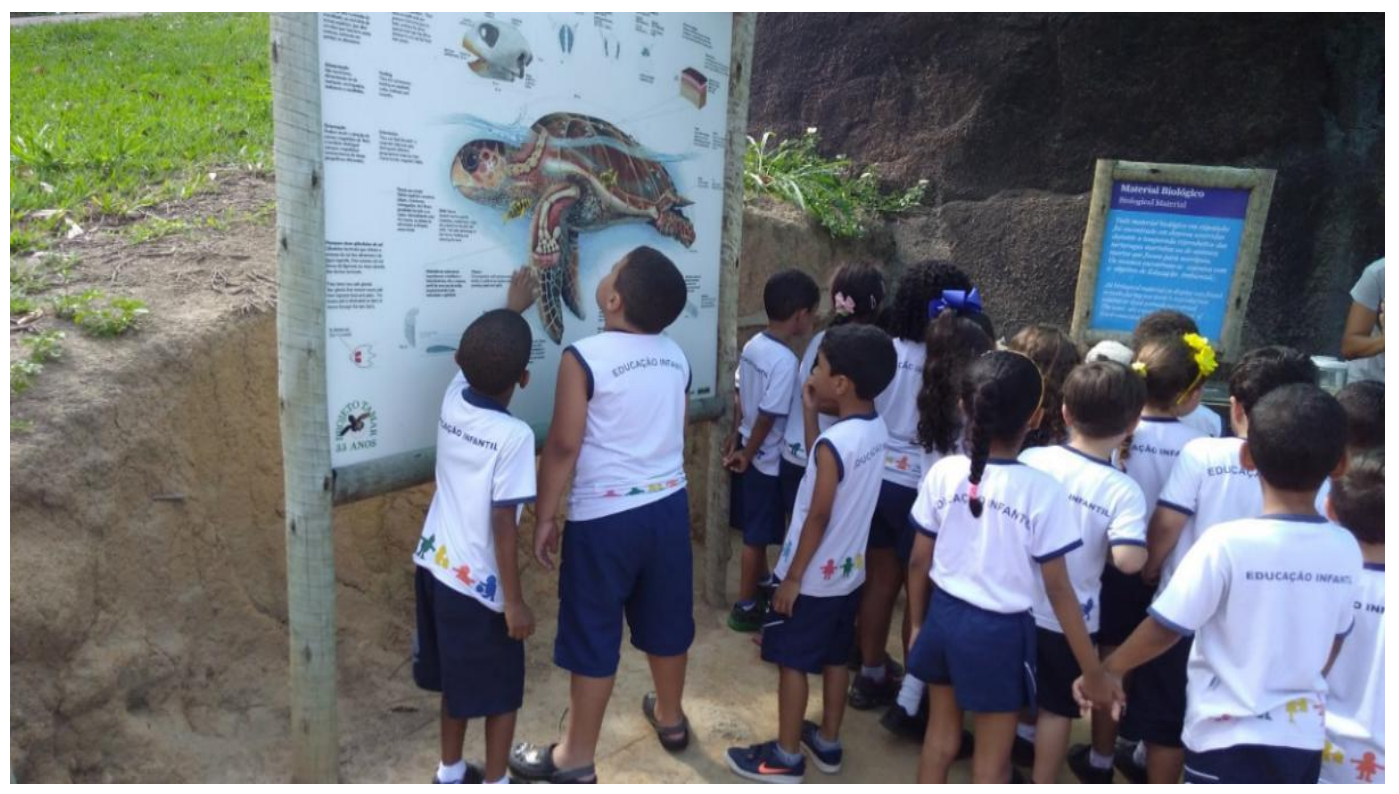

Figura 4 - Observações de informações sobre a tartaruga gigante.

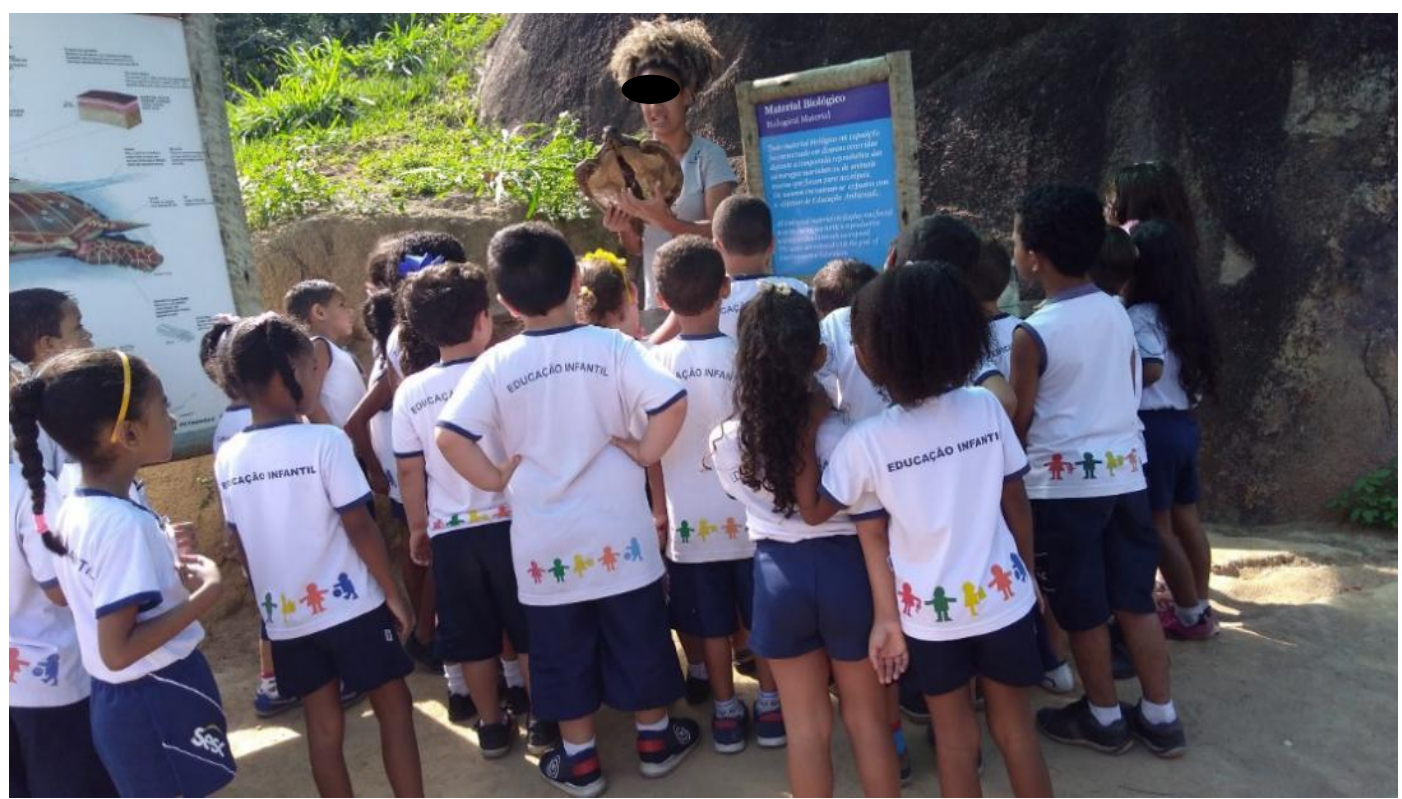

Figura 5 - Observação dos fosses dos animais marinhos.

O interesse em conhecer outros espaços do projeto TAMAR pareceu aguçar ainda mais a curiosidade e, a necessidade de observar e aprender mais sobre o meio ambiente que estava sendo explorado.

Para Ferreira e Mello (2012, p 18) os ambientes externos fazem melhor aos perguntadores, e os "[...] estudos do meio sempre foram importantes para experiências e, consequentemente, para a motivação de crianças e jovens." Compreende-se que os meios ambientes onde proporcionam visitações contribui para um ser criativo e dinâmico, tornando- 
os cidadãos mais observadores e conscientes sobre os problemas que atingem nosso meio ambiente.

\title{
Conhecimento prévio dos alunos
}

Valorizar neste momento o que a criança traz como conhecimento prévio enriquece muito as observações, o mais importante neste momento é ouvir e da voz aos alunos da Educação Infantil valorizando a vivencia já adquirida, observadas nas perguntas e respostas feitas pela professora e monitora:

\begin{abstract}
- O lixo no meio ambiente mata as tartarugas, eu vi no vídeo que assistimos quando chegamos; quando vamos na praia com nossas famílias, o que devemos fazer com o lixo que sobra dos alimentos que comemos ou levamos? Eu professora, eu! Pode falar, nós devemos levar uma sacola e colocar do o lixo dentro e depois quando a gente for embora colocar a sacola na lixeira.
\end{abstract}

O trabalho individual é potencializado pelas exigências feitas aos alunos para se responsabilizarem por suas ações, suas ideias, suas tarefas, pela organização pessoal e coletiva, pelo envolvimento com o objeto de estudo.

Ao valorizar a interação como instrumento de desenvolvimento pessoal, exige que os alunos considerem diferenças individuais, tragam contribuições." (PCN, 1998.p.90). Quando valorizamos a fala dos alunos podemos ver a satisfação e a segurança ao perguntarem e obterem resposta positiva e sistematizada com o contexto em que estão inseridos.

\section{Interação dos alunos no projeto TAMAR}

Concluiu-se que os objetivos da aula de campo foram atendidos, à partir das evidências demonstradas através de observações, perguntas, respostas, das curiosidades manifestas e, no entusiasmo de cada aluno ali observado, nos momentos de participações, caminhadas, descanso.

Considerando que a equipe envolvida estava capacitada para responder e acompanhar os alunos da Educação Infantil do nível 1, os momentos foram muito proveitosos. As perguntas e respostas aconteciam de maneira natural. Na visualização dos animais marinhos teve-se a certeza de estar-se frente a uma concretização de tudo que foi aplicado em aula nossos planejamentos diários. 
A equipe, enquanto educadores, tiveram grande entusiasmo ante a oportunidade de formar cidadãos críticos e, capazes de mudar e ampliar seus próprios conceitos, bem como de colocar em prática os ensinamentos até então oferecidos.

De acordo com Silva e Fachin - Terán (2013), os professores necessitam de maior capacitação para falar sobre temas científicos, mesmo não sendo sua área específica, pois as crianças fazem perguntas em todas as faixas etárias.

É importante que as atividades de campo, não aconteçam apenas como uma mera excursão, mas após um planejamento organizado da execução e execução, elaborados previamente e com a organização devida (ROCHA e FACHIN - TERÁN, 2010, p.20).

Observou-se que as perguntas infantis tinham como base, as aulas prévias em sala de aula. Desta forma pode-se fixar melhor o aprendizado e, nos colocarmos como professores mediadores frente as curiosidades dos alunos da Educação Infantil. Diante de todos os objetivos para realizar esta aula de campo, observar uma conscientização acerca do meio ambiente e de sua diversidade, foi muito gratificante para os educadores participantes. Eles pareceram demostrar maior cuidado e preocupação em deixar o local limpo, depositando seus dejetos ou sobras dos lanches nas lixeiras devidas. Esta consciência vem sendo trabalhada no ambiente escolar e, colocada em prática no cotidiano dos alunos da Educação Infantil.

\section{Considerações finais}

Pode-se então verificar que a interação com o ambiente visitado no projeto TAMAR mostrou-se eficaz. A aula de campo proporcionou momentos de grande aprendizado e envolvimento harmonioso entre alunos, professores e, com o novo ambiente apreciado.

Colocou-se em prática os estudos das aulas de meio ambiente em sala. Trata-se de uma proposta pedagógica importante e necessária, que se mostrou facilitadora do aprendizado com visível ganho para os alunos e a sociedade. Como se pode observar, o ambiente que nos cerca é repleto de expectativas e influência na motivação para as indagações, por expor os alunos a uma mobilização de sua curiosidade.

Tudo isso ficou mais concreto nas falas dos alunos da Educação Infantil como uma forma bem peculiar de perguntar. As indagações pareceram facilitar a vivência e práticas na sala de aula, aprimorando ainda mais o trabalho do educador, tornando-o mais prazeroso, dinâmico e significativo. 
O planejamento neste caso é imprescindível para nós professores que nos preparamos e adentramos em um ambiente pleno de possibilidades de adequação e, mudanças para tornar ainda melhor nossos objetivos frente ao meio ambiente.

As aulas de campo, possibilitaram consolidar as reflexões e possibilidades sobre o que é novo e diferente da sala de aula. Eliciou nos alunos expectativas capazes de gerar questionamentos múltiplos, despertando-os para uma relação intensa com o meio ambiente marinho.

No projeto TAMAR pudemos desfrutar de momentos de construção, apropriação e transformação, possibilitando aos alunos da Educação Infantil uma experiência única. Os trajetos que fizemos em torno do projeto TAMAR foi uma oportunidade de apreciar e comtemplar o meio ambiente, em que os recursos naturais presentes se mostraram bastante diversos e interessantes seja no mar, nas trilhas ou observando as árvores no trajeto.

Contudo a temática ambiental, possibilitou conhecer e praticar as relações e sobre o tema meio ambiente, ajudando na compreensão de que são as nossas atitudes que poderão mudar a qualidade da vida de muitos seres vivos, incluindo-se aí as pessoas e os próprios alunos.

\section{Referências}

BRASIL. Constituição da Republica Federativa do Brasil, de 05 de setembro de 1988. Senado: Brasília, 1998. Disponível em: www. senado.gov.br acesso em 04 de novembro de 2012.

BRASIL. MINISTÉRIO DA EDUCAÇÃO. www.portal.mec.gov.br/seb/arquivos/ pdf/introdução

CORSARO, William A. Sociologia da infância. Porto Alegre, Artmed, 2011.

FERREIRA, S. H.; MELLO, A.M. Um encontro entre a ciência e a educação infantil Revista Pátio- Educação Infantil. Entrevista. Ano X,n.33, Out/Dez.2012.p.16 - 18.

FUENTES, S. S .O porquê e o como das ciências na Educação Infantil Revista Pátio Educação Infantil. Entrevista. Ano X, n.33,out/Dez.2012. p.8 - 11

G1. REDE GLOBO. http://g1.globo.com/espirito-santo/noticia/2017/02/tanque-das-tartarugase-aberto-ao-publico-em-vitoria.html.

LIMA, M. M. S. A cidade e a criança. São Paulo: Nobel, 1989. 
LIMA, V. B; ASSIS, L. F. DE. Mapeando alguns roteiros de trabalho de campo em Sobral (CE): uma contribuição ao ensino de Geografia. Revista da Casa de Geografia de Sobral. Sobral, v. 6/7, n. 1, 2004/2005.

MACEDO, G,R,PIRES,T.T., ROSTANI,GG., GOLDBERG, D.W., LEAL,D.C., NETO, A.F.G.\& franke,c.r.,2011,Ingestao de resíduos antropogênicos por tartarugas marinhas no litoral norte do Estado da Bahia, Brasil. Ciênc. Rural.,41(1): 1938-1943.

MARCOVALDI. M.A.; PATIRI, V.; THOMÉ, J.C. Projeto TAMAR-IBAMA: Twenty-five years protecting brazilian sea turtles through a communitybased conservation programme. MAST. Amsterdam, v.3-4, n.1-2, p.39-62, 2005

MARTINS, M. Q. Sensibilização e Educação Ambiental. INA.II Encontro Internacional de Educação Ambiental dos Países Lusófonos e Galiza. Cidade da Praia. Disponível em: http://repap.ina.pt/bitstream/10782/352/3/Sensibiliza\%c3|\%A7\%C3\%A30\%20e\%20Educa\% C3\%A7\%C3\%A30\%20Ambiental.pdf>. Acesso em:30Jun.2010.

MURMANN, L. et al. Qualidade do armazenamento de alimentos em estabelecimentos comerciais da cidade de Santa Maria, RS. Revista Higiene Alimentar, v. 19, n. 147, p. 29-33, 2005 .

PROJETO TAMAR. www.tamar.org.br/interna.php?cod=63

ROCHA, C. C.; FACHÍN - TERÁN, A. O uso de espaços não - formais como estratégia para $o$ Ensino de Ciências. Manaus: UEA Edições, 2010. 136p.

SILVA, C. C.; FACHÍN-TERÁN, A. A utilização dos espaços não formais como contribuição para a Educação Científica: uma prática pedagógica (que se faz) necessária. In: FACHÍNTERÁN, Augusto; SANTOS, Saulo César Seiffert (Orgs.). Novas perspectivas de ensino de ciências em espaços não formais amazônicos. Manaus: UEA Edições, 2013. p.53-63.

\section{Como citar este artigo (Formato ABNT):}

DOMINGOS, Lucilene Emidio; SILVA, José Geraldo Ferreira da. Aula de campo no projeto TAMAR: conscientizando alunos do nível 1 da educação infantil, sobre os cuidados e sobrevivência das tartarugas no habitat de proteção. Id on Line Rev.Mult. Psic., Maio/2020, vol.14, n.50, p. 823-834. ISSN: 19811179.

Recebido: $12 / 12 / 2019$

Aceito: 08/05/2020 